\title{
Thematic and Stylistic Appraisal of Sculpture in Public Places in Nigeria: The Example of Southwest
}

\author{
M. A. Akintonde and R. O. Rom. Kalilu \\ Department of Fine and Applied Arts, Ladoke Akintola University of Technology, Nigeria
}

\begin{abstract}
Outdoor sculpture in Southwest of Nigeria is fast growing in practice and art historical values. Since its emergence in 1934, it has developed different modes in practice which have not been given proper art historical consideration. The nature of the fleeting practice, poor maintenance and preservation as well as constant loss of works portends serious art historical gap if left unattended to. It is therefore imperative that studies on the outdoor sculpture practice be conducted from time to time. In this study, themes and styles of the outdoor sculpture in the Southwestern Nigeria from 1900-2005 were examined. The period under study represents the emergence to the proliferation period of the practice. The outdoor sculptures within the period were enumerated and classified under form, style and material for proper analysis. Themes and styles from the samples of the works were specifically studied. Findings in the study reveals that thematic consideration in all the works were basically hinged on socio-political and economy state of the zone at each developmental phase. Forms were mainly expressed in realism with variation in each artist's style. The study was conducted to place the themes and styles expressed in the nascent art on art historical record in the main stream contemporary Nigerian art. Significantly, the study is hoped to provide information and stimulate further studies in the related scholarly area.
\end{abstract}

Keywords: aesthetics, outdoor sculpture, public art, style, theme

\section{Introduction}

The use of outdoor sculpture for environmental beautification and sacred objects among Yoruba of Southwestern Nigeria is long in history. Records of the use of sculptures for the decoration of kings' palaces, community leaders' houses and shrines environments have been well documented in art historical studies and related disciplines published by numerous scholars such as Adepegba (1995), Bascom (1973a and 1973b), Fagg (1990), Idowu (1977), Kalilu (1992:49-63 and 1995:18-42), Robert (1973:19-61) and many others. The tradition and the mode of practice of the art were hinged on religion, social, political and economic needs of the people. These factors were carefully considered in visual representation and controlled by Yoruba aesthetic canons (Abiodun 1987:65-87).

At the emergence of contemporary art in Nigeria, traditional religion with all its influence on social, political and economy of the Yoruba declined drastically, giving way to new Western culture. The Yoruba quickly assimilated new culture and redirect the use of sculpture basically for secular functions. Sculpture that was hitherto confined into the shrines and other sacred places in the traditional Yoruba communities became objects of environmental beautification and memoriam art. No sooner, the outdoor sculptures were used for environmental decoration by individuals that could afford the cost around 1905 than the church became the largest patron of the art. By 1934, the Colonial Government in the Southwestern Nigeria had commissioned a foreign artist to produce Ogedengbe staff, a commemoration of the veteran Ijesa war-lord. The Ogedengbe Staff (plate 1) was erected in front of Owa's palace at Ilesa. In 1948, the image of Unknown Soldier popularly known as Sojadumota was produced and erected at Idumota area in Lagos. Since then, outdoor sculpture in the Southwestern Nigeria has witnessed tremendous developmental phases in time and space.

The practice of the art has its nuances that contribute to its growth. Parts of the mode of practice which prime considerations are given to are the thematic and stylistic expressions of forms in accordance to the contextual basis of the works. The two elements of expression in art amongst others are fundamental to the practice of outdoor sculpture generally among the Yoruba and it is of great values to the art historical study of the works in the zones. The development of outdoor sculpture in the Southwestern Nigeria reveals thematic, form and stylistic dynamism inspired by prevailing socio-political and economic tendencies in the country. However, the development affords an impressive art historical study which will provide outdoor sculptures record in the general body of contemporary Nigerian art. 


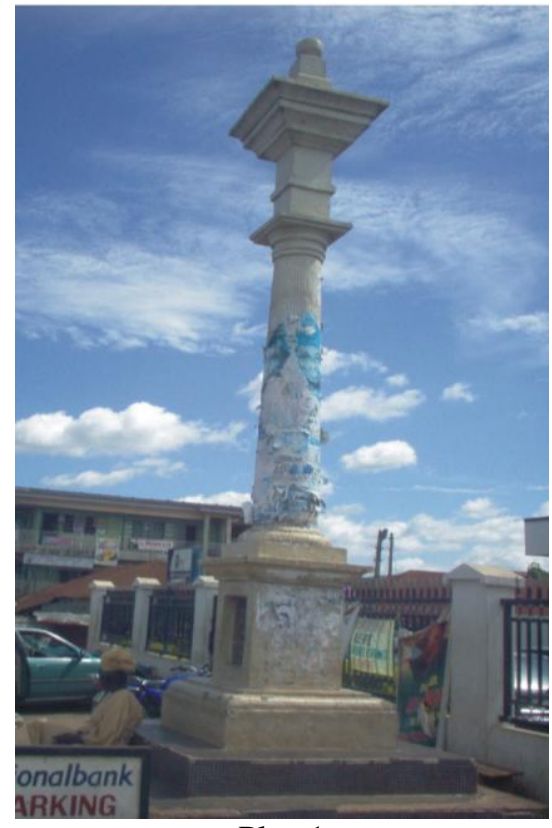

Plate1

The Ogedengbe Staff, cement and ceramic tiles, height: 480cm, 1934, Ilesa.

Photograph by Akintonde Moses, 2007

Scholarship on the practice of outdoor sculpture in Southwest of Nigeria is still limited. Apart from Odiboh (1987), Adewolo (1999) and Akintonde (2004:15-27) that discusses outdoor sculpture in some cities of southwest generally; Akintonde (2009) who however provided more details premised it on general attitude of the art. Other studies on the subject are peripheral, for instance, Folarin (1993), only made a passing remark on the poor concept, form and technique in the practice of outdoor sculpture in Nigeria, using Basorun Ogunmola at Total Garden Ibadan as an example of such poor works . Other scholar that discussed outdoor sculpture elsewhere is Ikpakronyi (1997 and 2005); whose studies are also general in scope. Although the studies of the scholars are good in their targeted scope but they have not sufficiently discussed the thematic and stylistic nature of the art. Bearing in mind that the ephemeric nature of some aspects of the practice could easily becloud future scholarship in the venture, because sculptures are usually damaged, completely removed or replaced due to religion or political exigencies. Recently, mass adoption of roundabout, T-junctions and parks were made by banks and other corporate bodies in Lagos, Ibadan, Osogbo and Ado-Ekiti primarily for product advertisement uses. Removal of existing sculpture in favour of another or non sculptural matter such as sign posts landscaping of their business outfits were common practice now. This idea is apt to disrupt opportunity to studying outdoor sculptures over a period of time. For these reason, scholarship on the extant works is important and expedient if a good art historical track record on the zone would be maintained.

This study is based on examination of themes and stylistic variance expressed in the public sculpture in the entire Southwestern Nigeria. The objective of the study is based on the development of the practice in terms of flexibility and dynamism of themes and styles hinged on the prevailing social political state of the zone placed in art historical context. The sculpture in public space in the study, refers to; outdoor sculptures erected in T-junction, road highland, roundabout, parks and gardens that are opened to the general public.

\section{Appraisal of the Works}

The purpose of any art is to provide aesthetic appeal and serve utilitarian functions, if need be, and to inter in them historical element within the context of their make and existence. For this reason, the artists abide with a general formula that would make their works acceptable to the end users. These elements that create aesthetic appeal and utility of form in art have been identified as: form, style, technique and themes (Graves 1951:19-61). These are the wall blocks carefully put together to create order and sensibility in art.

Generally, the contemporary art of the Southwest of Nigeria did not enforce a format of expression as in the traditional Yoruba sculpture, which has been well articulated by Thompson (1973: 19-61) and Abiodun, Drewal and Pemberton (1991:65-87) in separate publications. However, because the people, whom the art were made for, are still the same, despite some shifts in culture towards the Western or European art canons, yet a lot of traditional art canons were retained by the Southwestern Nigerian sculptors, to keep their cultural identity intact. They cannot escape working within the Yoruba cultural milieu if their art must be made meaningful and 
acceptable to the people. The artists in the zone have therefore responded very well to the Yoruba culture and current socio-political issues in their expressions.

As a result of this, abstract, realism and naturalism were all used in the expression of forms of the sculpture in southwest. The one mostly used among these styles is realism. However, many works expressed in realism did not reflect high sensibility reminiscence of the Yoruba traditional art aesthetics. This is easy to deduce because some of the works are naive and poorly finished. Their low qualities are not a deliberate intension to portray simplicity of form. A close observation of some of the works betrayed the artists' lack of understanding of the Western style format, which they seemed to largely employ. Despite the exposure to Western art education with its inherent rules in the rule of measure naturalism as found in the Renaissance, it has not been possible for many of the artists to express their forms in good realism.

It is observed that there is a general style acceptable to the public in the production of contemporary outdoor sculpture in the Southwest. That notwithstanding, it is still not possible to determine the occurrence of communal style as in the traditional Yoruba sculpture (Fagg 1990:120 - 121). This may be premised on the function which the art now serves. Art today is not based on religious functions that must bear specific icons hinged on conceptual expression (Kalilu 1995:28-42). In the 20th and 21st centuries, religion undoubtedly promoted Yoruba art but the art was not totally based on it. Functions also did not restrict the forms of the sculptures.

However, despite its perpetual use of traditional genres either as themes or as motifs the outdoor sculptures are to be enjoyed like other objects of beauty rather than religious objects. Their capacity for the enhancement of easy traffic flow at round about and T-junctions, and compliment environmental beautification with sensual appeal justify the production and perpetuation of the sculptures in various forms and styles. This also had helped individuals evolves their own style irrespective of their cultural background or communal affiliation. Some of the sculptors such Akah Bunak, are of Igbo extractions while others like Kunle Shariki and Adeola Balogun whose works were located in Ibadan and Lagos respectively are Yoruba who are or not even resident in the places where their works were located.

Nevertheless, the theme expressed in the sculptures leaned much on the Yoruba cultural issues. A high percentage of the works commemorates communal ancestors such as: the founders of towns, war lords who had secured victory for their people in political struggles or wars of expansion, and statesmen in different historical epochs. Important figures so represented like these are strictly from the people's traditional background. Examples of works in this category are: Statues of Owa Ajibogun in Ilesa (plate 2), Ajagunnla in Ila-Orangun (plate 3), Iba Oluyole in Ibadan (plate 4), Oronshen, Renregenjen and Ayooyo in Owo (plate 5) and a host of others. Statesmen such as Obafemi Awolowo (plate 6), the political sage of Nigeria and MKO Abiola (plate 7), a business mongol and political martyr of modern Nigeria, were captured in vivacious political actions reminiscence of the icons.

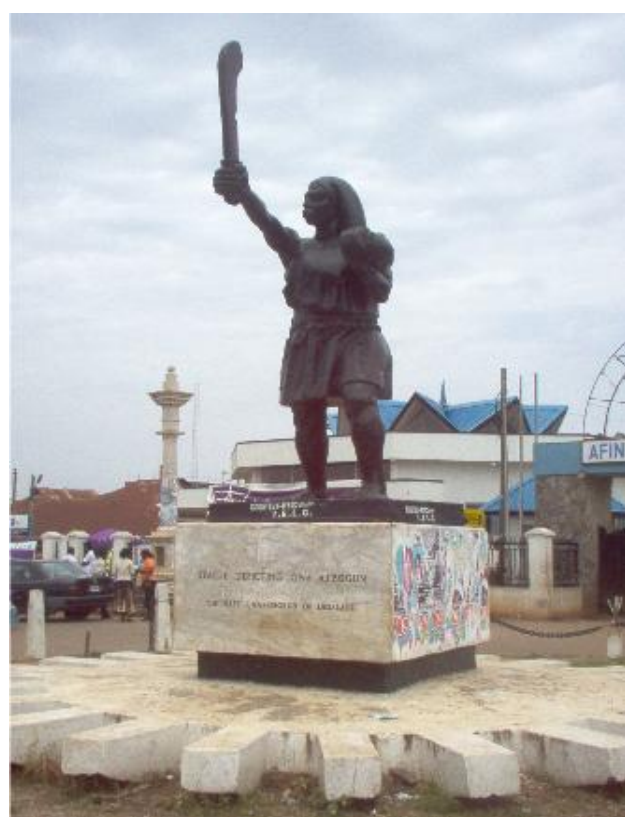

Plate 2

Joe Erigar, Owa Ajibogun, cement, height: 270cm, 1986, Ilesa.

Photograph by Akintonde Moses, 2007

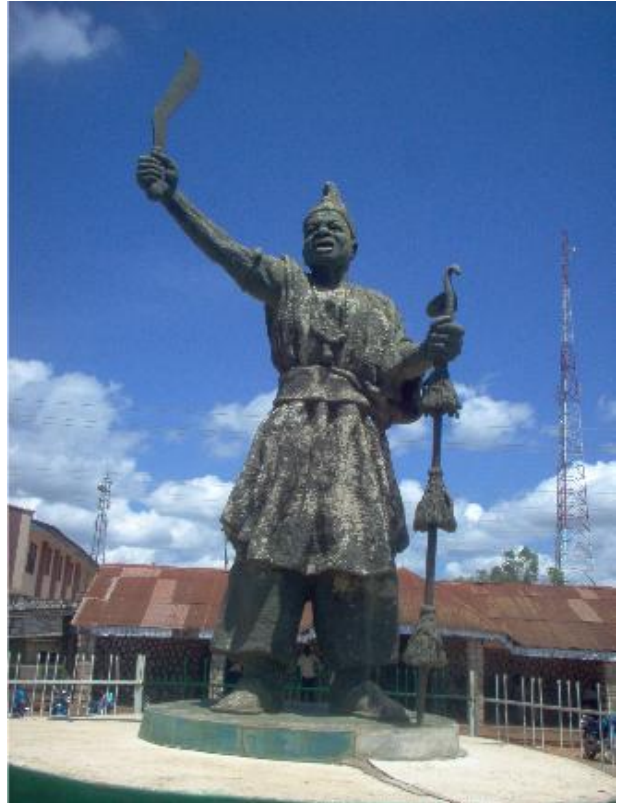

Plate 3

Akintonde Moses, Ajagunnla, cement, height: 270, 1987, Ila-Orangun

Photograph by Akintonde Moses, 2007 


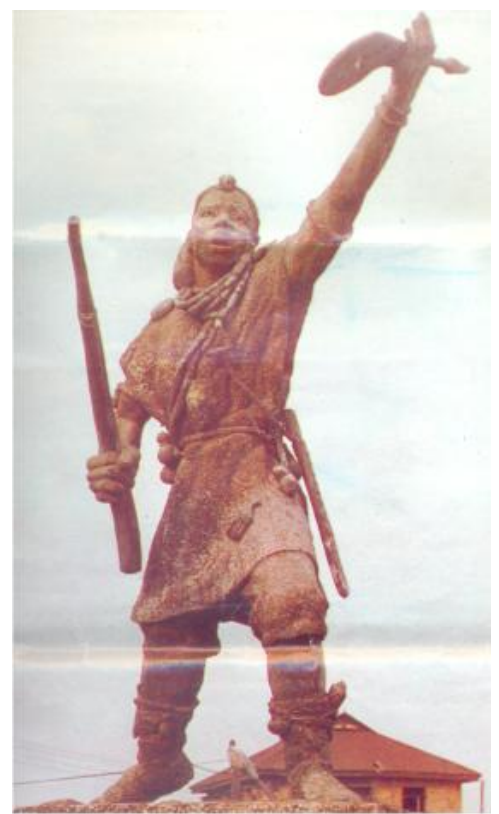

Plate 4

Tiri Oladimeji, Iba Oluyole, cement, height: 300m, 1987, Beere, Ibadan. Courtesy of Trans Assurance Plc., 1996

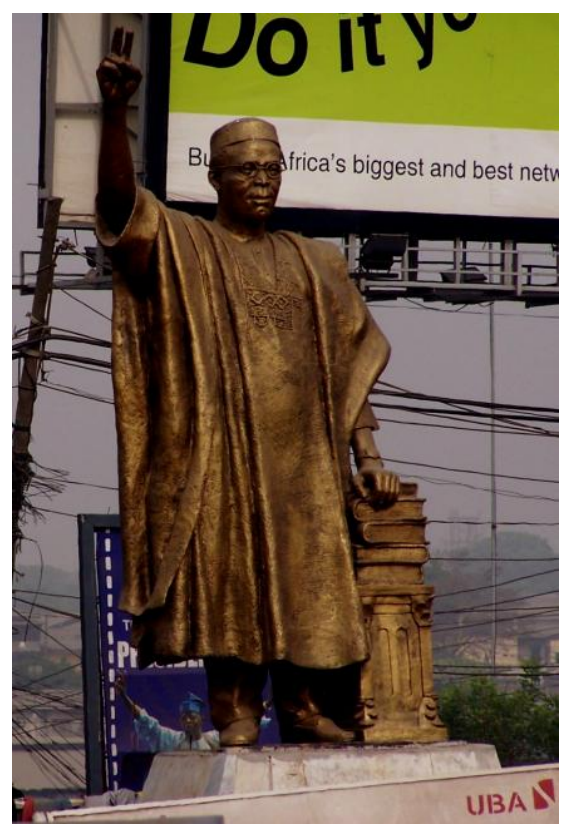

Plate 6

Adeola Balogun, Obafemi Awolowo, fibre glass, height: $240 \mathrm{~cm}, 2002$,

Allen Junction, Ikeja, Lagos.

Photograph by Akintonde Moses, 2007

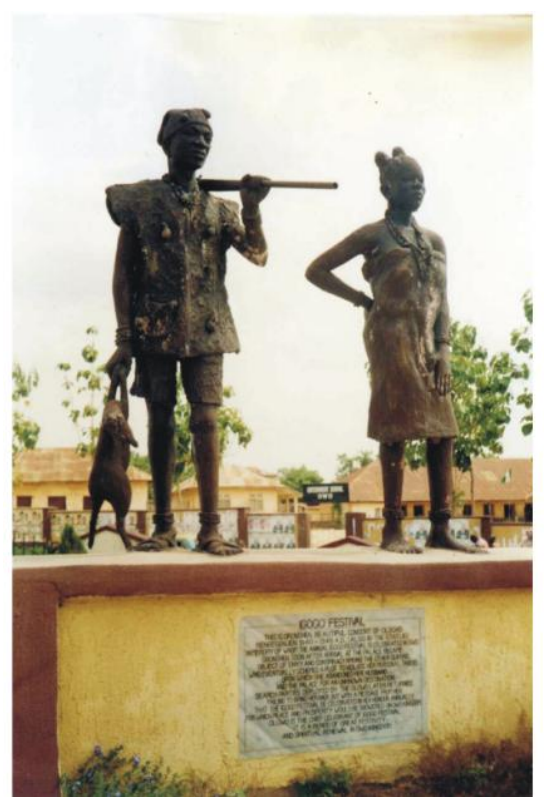

Plate 5

Oronshen and Renregenjen, cement, height: 150, 2004, Olowo Place, Owo Photograph by Akintonde Moses, 2006

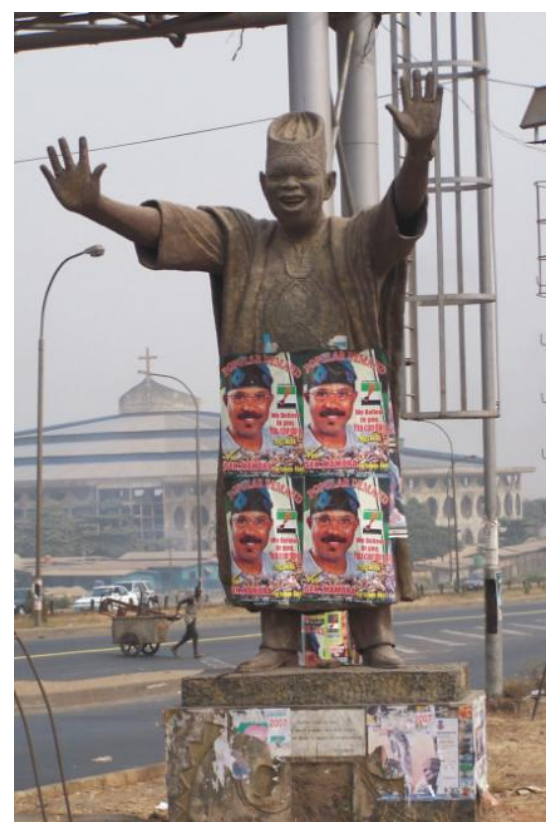

Plate 7

Familehin Sola, MKO Abiola, cement, height: $270 \mathrm{~cm}$, Ojota, Lagos Photograph by Akintonde Moses, 2007

A common feature in contemporary outdoor sculpture that cuts across the Southwest is the military theme. This is expressed in many variations and it is known as Unknown soldier. The local name ascribed to this type of sculpture through out the zone is Sojadumota. It is a name given to the first of its kind in Nigeria (plate 8), which was formally located in Idumota area of Lagos. Other themes employed by the outdoor sculptors are images that give civic instructions to the public and those that portray the occupational and vocational peculiarities of different Yoruba groups (plates 9 and 10). Non-figural forms are common in the Muslim dominated towns such as Ilorin and other towns in the northern part of the country. 


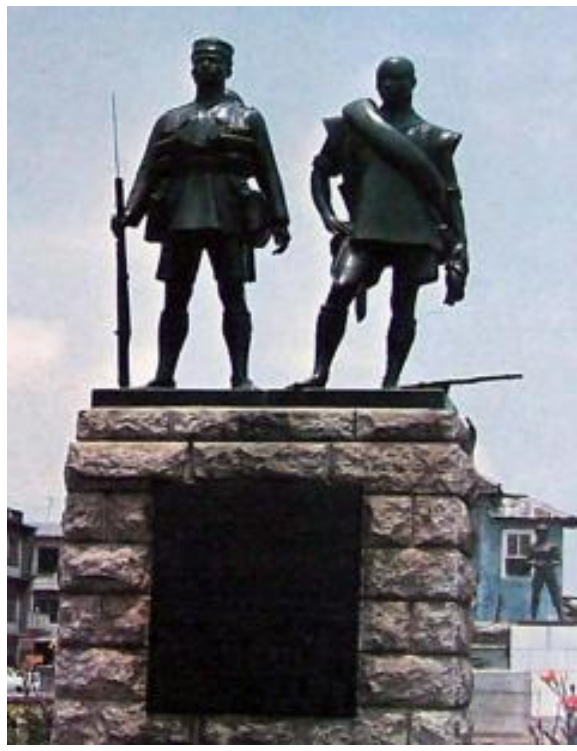

Plate 8

Cenotaph of Unknown soldier, bronze, 1948, Idumota, Lagos.

Courtesy of Ajayi Oladele, 2007

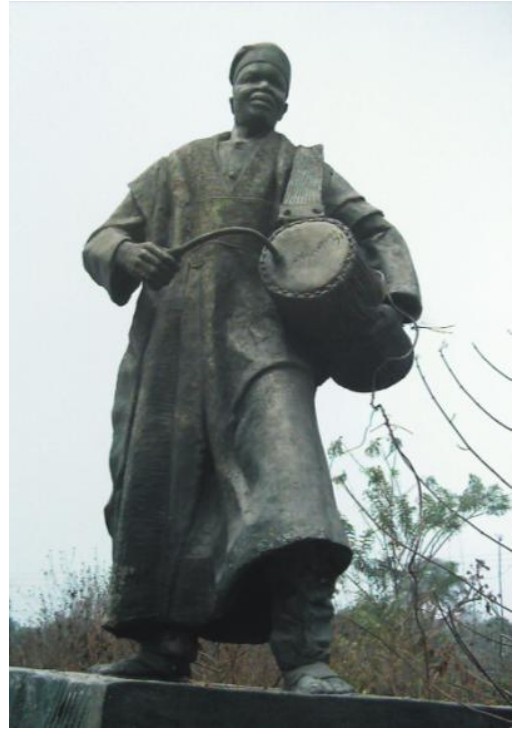

Plate 9

Akintonde Moses, Dundun drummer, cement, height: 220, 1998, Ikirun-Ilorin Road Osogbo Photograph by Akintonde Moses, 2005

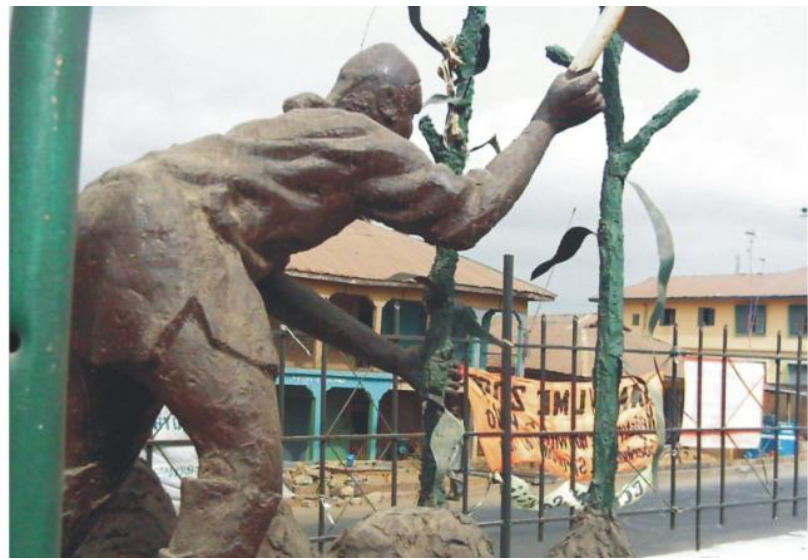

Plate 10

Adejumo Isaac, Alokomaro, cement, height: 180cm, 1993 Alokomaro, Ogbomoso

Photograph by Akintonde Moses, 2007

\section{The Images and their Thematic Expression}

The sculpture samples discussed here were selected based on their perceived thematic importance and technical proficiency. They are nonetheless carefully selected across all the groups of the outdoor sculptures in the region. In all, eight were discussed. They are located in Kwara, Osun, Oyo, Ondo and Lagos.

Iba Oluyole (plate 4): This sculpture is located at Beere in Ibadan. It portrays the warfare prowess of Iba Oluyole, a nineteen century Ibadan warlord. The image had a full traditional martial uniform, a short men buba, (blouse), and sokoto, a trouser with charms tied round the waist. On the left hand is a gun which he held diagonally, while the right hand raises a gigantic sword up in the air. The whole body shifts forward in advancing position and the total weight is balanced by the forward inclined left leg. The facial expression portrays alertness and confidence. The work was erected on a two-step pedestal. The lower pedestal measured $120 \mathrm{~cm}$, while the upper one is $90 \mathrm{~cm}$. There are illustrations of previous acts of the warriors on a low relief attached to the higher pedestal. The Iba Oluyole statue was rendered in realism with good anatomical rendition, but the left hand is slightly larger than normal size and thus disproportionate to the body. Tiri Oladimeji, the sculptor, effectively executes surface texture on the statue to correspond with body structure draperies and perhaps the tense atmosphere of the war the action captured. The figure has a strong sharp texture, emphasizing 
the garment while the flesh is given a sensuous smooth texture. A tempered metallic gold colour is skillfully used for the patination of the statue.

Welcome (three white cap chiefs): The three white cap chiefs (plate 11) sculpture erected formerly at the Lagos-Ibadan toll gate area welcomes people of deferent clans to Lagos. The three manners of traditional greeting in Eko (Lagos) were portrayed and displayed by the images of the traditional high chiefs, the Idejo, in flowing white wrappers tied across their shoulders. They all had white caps on their heads (their official costum). All of them are in slightly varing standing positions. The figures on the right hand side stretch his fist forward, in the air. The one in the middle holds his right fist forward, inclined a little down, while the figure on the left hand side clinched his two fists together, slightly touching each other in the air. These forms of greetings are the highest honour that can be accorded anybody in the Eko greetings tradition. In the figure, Bodun Sodeinde who executed the work conceptually portrayed Lagos as a rich land of opportunities, readily welcoming all categories of people from near and far to come and try their lucks in business in the city. There is a saying in Yoruba that connote the flexibility nature of Lagos; Eko gbole, o gbole (Lagos is home to all kinds of people). Represented in realism, the figures are massive and muscular like works of Michealangelo but without the master's stroke, expressive with ample anatomical details. The heights of the figures are approximately $480 \mathrm{~cm}$. They are cast in fibre glass and partinated with white colour. Placed upon a high and massive pedestal, the figures are imposing and can be viewed from any direction.

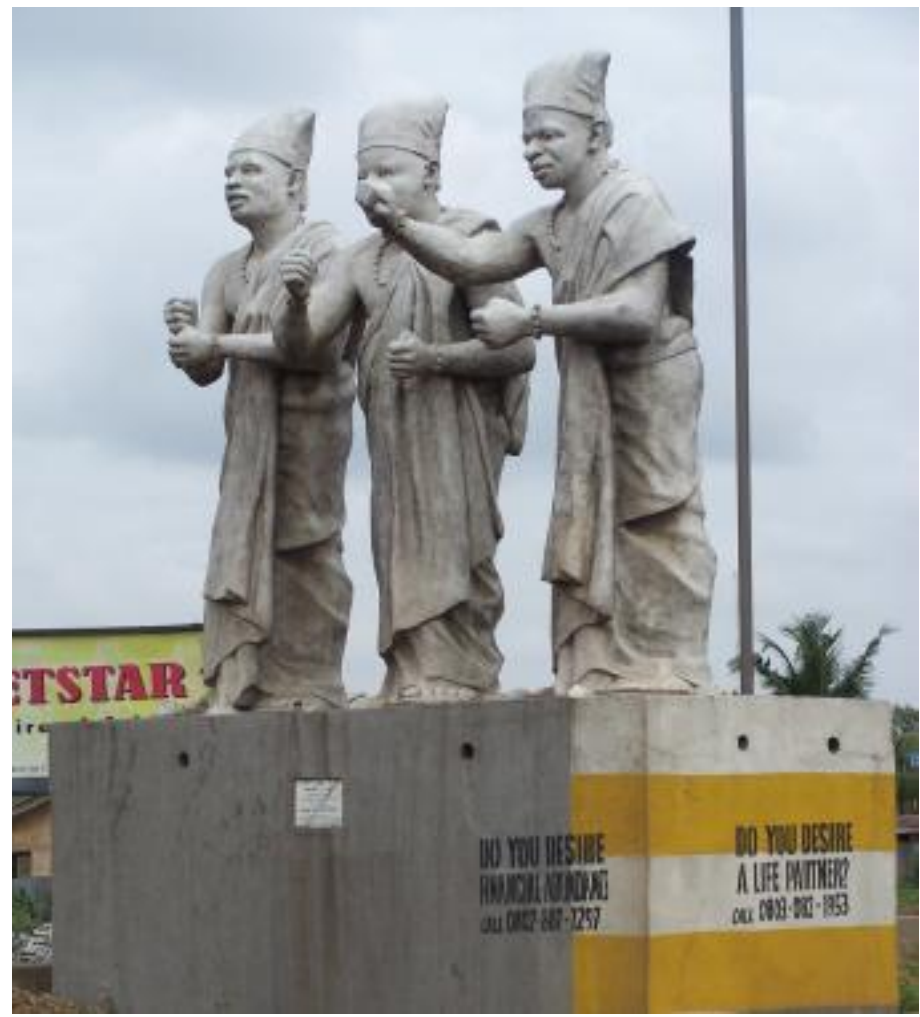

Plate11

Biodun Sodehinde, Three Idejo chief titled Welcome, fibre glass, height: 240cm approx., 1991

Photograph by Sola Ogunfuwa, 2007

The statue of Herbert Maculay: The status of Herbert Maculay (plate 12) adorned the Sabo area of Merculay Street in Lagos in remembrance of his patriotic feat. Merculay was a nationalist who pioneered the struggle for Nigeria independence. His political party, Nigeria Democratic Party in the 1920s is still fondly remembered today. The statue was made by Tolu Filani, a one time Yaba College of Technology, Lagos Art Lecturer. The statue, slightly above life size, is erected on a high pedestal, presenting a good view from all sides. Made in fibre glass cast, it is one of the best sculptures approached in naturalism style in the southwest. With excellent resemblance and a good capture of the inner character of Merculay, it is graceful and subtle, well expressed in free flow of drapery, minute detailing of forms and facial expression. The skill of the artist and his technical proficiency are comparable to the sculptural figures of the "High Renaissance". 


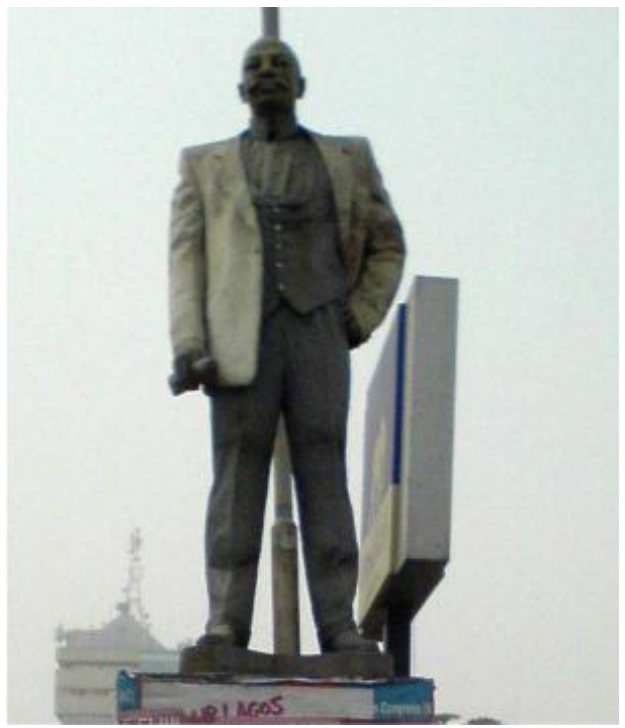

Plate12

Tolu Filani, Herbert Macaulay, fibre glass, height: 480cm, 1934,

Herbert Macaulay Street, Sabo, Lagos.

Photograph by Sola Ogunfuwa, 2007

Awolowo (plate 6): In politics particularly when considering right for an egalitarian society, Obafemi Awolowo, a legendary figure in Nigeria politics is remembered in several ways in Nigeria. His struggle for Nigerian independence is well known in history. His yearning for education for all school age children in the Southwest is also well remembered today. These attribute are entrenched in the statue commemorating Awolowo (plate 6), erected in Allen area of Ikeja in Lagos State. Ikeja where the statue was located is an appropriate one. It is the seat of power in Lagos State where most of Obafemi Awolowo's political actions were instituted. The theme of the sculpture reflects Awoism. Awo, as he is popularly called in the political circle, was portrayed in a big flowing gown-agbada. The face of the statue is gentle and serene. It seems to look straight into the future of his people and the country. The image stands erect, raises up the right hand with the two index fingers in a "v shape" (victory sign) commonly displayed in greetings by his political parties, the Action Group in the 1960s and Unity Party of Nigeria between 1979 and 1983. Awolowo's political strength is the high level of educational attainment in the Southwest of Nigeria. This point is clearly depicted in the statues. At the left hand side of the image, a pile of voluminous books was creatively arranged symbolizing his wealth of wisdom and the free education programme he instituted in the Southwest. The left hand rests on the volumes of books seemingly echoing the heritage Awo left for his people. The work was patinated with metallic gold metaphorically depicting Awo's value. The colour, metallic gold, here symbolizes priceless value and perseverance, engendered by the durability of gold against severe weather conditions. The high marble-tiled pedestal also projects the sage's lofty achievements, metaphorically presented for all to see.

Monument built in remembrance of Kudirat Abiola (plate 13 and 14): This is one of the best contemporary outdoor sculptures in which political struggle in Nigeria was lucidly illustrated by Kenny Adamson, (a cartoonist) located at Seven-up Junction, Ikeja, Lagos. The sculpture was made in memory of the martyrdom of Kudirat Abiola who was killed in her struggle for the actualization of the annulled June 12, 1993 presidential election which was believed to have been won by M.K.O Abiola, her husband. The work is a fibre glass cast two sided bas-relief. On the $360 \times 390 \times 90 \mathrm{~cm}$ relief are figures with different poses of Nigerians, sighing and crying under the heavy political oppression and economic hardship. There are eight figures arranged in two rolls, four people on each row, on the front row of the relief towards west. On the back row of the first figure is a lean tall figure of a man in bonds. It was carefully expressed portraying abject poverty and political servitude in the land. The neck tilted forward; with the face bowing down. The clavicle as well as the chest bones in the image protrudes. Next to the figure is a fettered man raising up his arms while the bond chain dangles. Following it is a contorted dejected female figure, simply dressed in a wrapper. The one beside the figure bowed down her head and clamped her bond hands on her tight.

On the front row, the first figure from the right hand side is in chains inclining her head to the left side. The central figure is a mother carrying her dead son probably killed in the "June 12" political impasse riots. It vividly portrays agony of a mother whose probable hope in an only child was dashed in a fiat. The head of the dead body dangles and so also are the hands and leg downward in the air. The last figure to the right on the row is a boy who took a pitiful look on the dead body. 
The other side of the relief however, quickly bailed its audience out from grieve and dismay of a vermin nation (plate 14). A nation managed by a despot whose firepower snuffed life out of many political activists and some of the Nigerian best brains. The figures on this side were made in three rows of three figures in the front, two in the middle and three at the back. All the figures had their bonds broken. The action was a wild excitement and spontaneous jubilation, metaphorically marking the incredible news of the death of General Sanni Abacha, the then Military Head of State of Nigeria and the instant victory of "democracy". Five of the eight figures threw their hands into the air in victory, while the other three happily looked at different directions. The portrait of Kudirat Abiola was made in low relief on both sides of the relief. When viewed against the major figures in the work, Kudirat's portrait is too invisible at a short distance away from the work. All the sides of the work, including empty spaces in the back and front, were given deep etching linear designs. The work, patinated in metallic bronze colour was erected on an angular $390 \mathrm{~cm} \times 120 \mathrm{~cm}$ pedestal. The work occupies a triangle shaped space of land, well fenced and provided with garden seats made suitable for people to relax in.

The artist adopted a specific manner of poses for the figures. Figures on both sides of the panel inclined their head on either sides in a symmetric order to express agony or victory in different ways. Although the work was poorly attempted in realism, yet, it was presented in an animated manner, typical of cartoon production. At least, Kenny Adamson, the artist, managed to give instant meaning through the composition to the political history of Nigeria between 1993 and 1999. The cenotaph was commissioned by the Lagos State Government. It was jointly unveiled by the Governor of Lagos State, Bola Ahmed Tinubu and Abraham Adesanya, the leader of Afenifere (a pressure group in Nigeria) on Sunday, 4 June 2000.

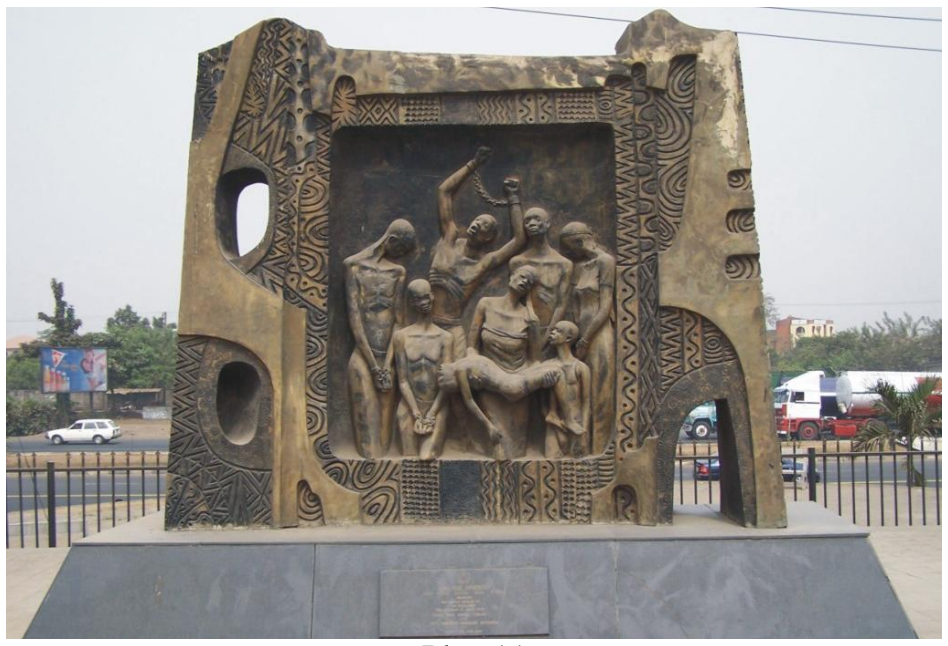

Plate11

Kenny Adams, Monument to Kudirat Abiola, fibre glass, $(390$ x 360 x 90)cm

2004, Seven-Up, Ikeja, Lagos

Photograph by Sola Ogunfuwa, 2007

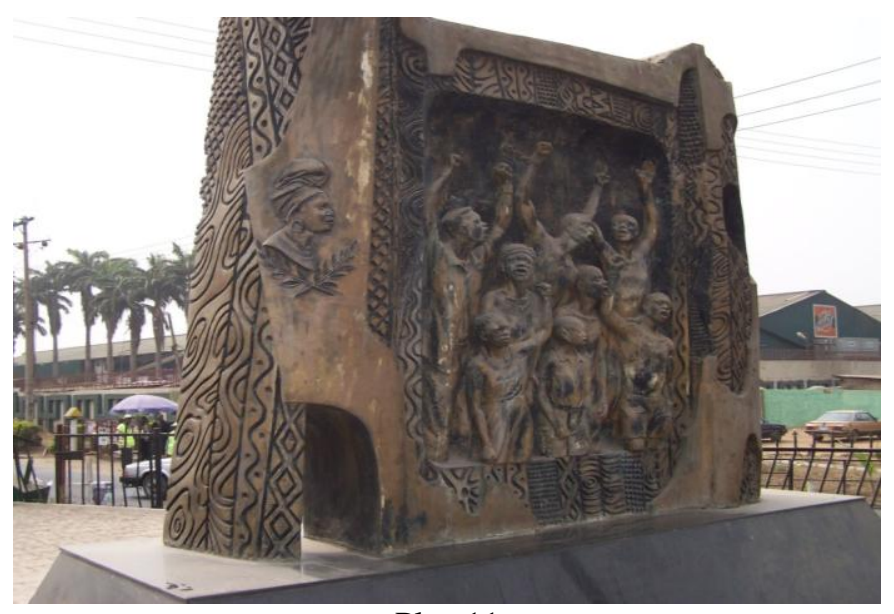

Plate11

Another view of Monument to Kudirat Abiola

Photograph by Sola Ogunfuwa, 2007 
Another public sculpture thematically expressed like the one above is Monument built in remembrance of the bomb blast victims (plate 15). The Monument built for the memory of the victims who lost their lives due to a bomb blast in Ikeja Cantonment of Sunday 27 January 2007 is profound and solemn in meaning. The abstract geometric sculpture erected beside Oke-Afa Canal in Lagos, represents another history in wanton waste of properties and human lives in Nigeria. The sculpture was unveiled on 16 February, 2002 by the government of Asiwaju Bola Ahmed Tinubu, the Governor of Lagos State. The epitaph on the sculpture reads: "In the knowledge that they rest in peace".

Standing on the area of $420 \mathrm{~cm}$ square, the sculpture is approximately $450 \mathrm{~cm}$ in height. The lower parts are rectangular shapes submounted on each other in a gradating order. The middle section is portrayed in an angular form, punctuated by a recessed rectangular shape also submounted by an arrow head shape with the Lagos State flag (red, blue, yellow and green colours) hoisted on the tapest part of the form. The flag probably symbolize the empathy shared by the entire people of Lagos state with the dead. A crescent and a cross signs are represented alternately on each side of the middle section, denoting the major religions of the victims.

The location of the sculpture could not have been more appropriately made any where than beside the canal where the victim's lives were extinguished in a sweep; traditionally, corpses of drown victims are buried at the bank of the river where the incident occurred. The somber atmosphere of the canal environment contributed immensely to the meaning of the work. For instance, the sculpture was sited against the background of dark stinking water, which may further aggravate apparent dejection of the public. Here, the declaration of Boccioni, an artist, came into the fore. He stated that outdoor sculpture and the environment it occupies complement each other in meaning and aesthetic (Herbert, 1989:43-44). Thus, the environment is part of the outdoor sculpture erected in it. The following epitaph was etched on the monument:

Here lies the victims of the bomb explosions from the Armory of Ikeja Military Cantonment More than a thousand innocent lives including Children scampering for safety perished in the Blackish Waters of the Oke-Afa canal (Ikeja Bomb Blast Victims Memorial 2004).

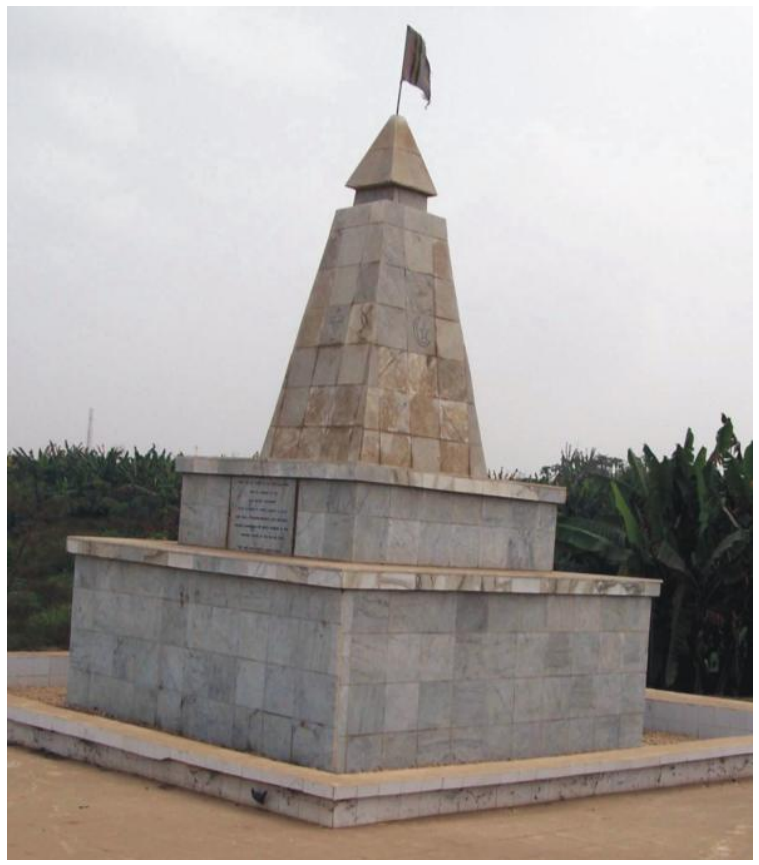

Plate15

Monument to the Ikeja Cantonment bomb blast victims, cement and ceramic tiles, height: 450cm, 2002, Oke Afa, Lagos Photograph by Sola Ogunfuwa, 2007

In the sport group, only one outdoor sculpture figure is significant in the Southwest, although, there are few other similar sculptures, such as the wrestlers at Offa, which are generally attempted in idealized realism, however, they are weak in composition as well as in technical proficiency. That notwithstanding, the footballer erected at the Liberty Stadium junction, Lister area, Ring Road, Ibadan is a classical example of realistic 
outdoor sculpture in the Southwest. The work (plates 16) was well composed in a breath taking poses, true of a skillful football dribbler such as Okocha ( a renown Nigerian footballer).

The work, expressed in good symmetric balance is skillfully made to reflect correct anatomical structure of a youthful athlete. The body swing and the finishing of the sculpture are similar to Michaelangelo's figures. The artist's reinforced cement material handling is also excellent. Although the surface of the work is smooth shining, an attempt was made to express the difference in the complexion of the body, the jersey and the boots of the footballer. The skin of the footballer reveals the youthfulness of an athlete and the exerted energy. The veins of the body around the elbow region to the fore-arm pop out, almost revealing the blood flow from the artery to the other parts of the body. The figure was erected on a four feet high pedestal, carefully positioned against the sunlight. In the morning, the sun rays fall upon the light grayish sensual body from the left hand side. The light dissolved into the forms on the right side. This also accentuates a clear definition of form. During sunset, the process is repeated vice versa.

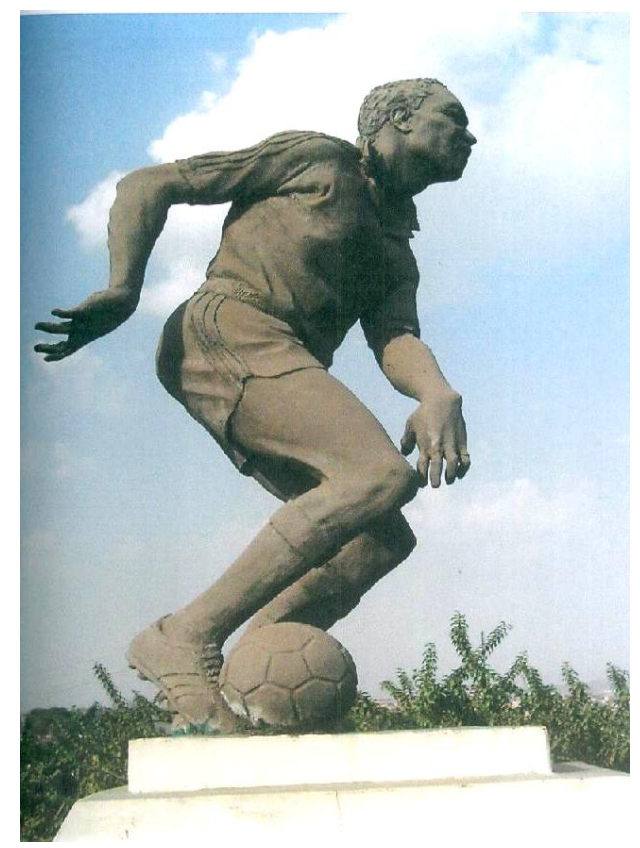

Plate16

Kunle Seriki, Footballer, cement, height $180 \mathrm{~cm}, 1989$,

Liberty Stadium Junction, Ibadan.

Photograph by Akintonde Moses, 2007

Only two equestrian figures were identified through-out the Southwest of Nigeria: one erected at Total Garden Junction, Ibadan, the other at GRA junction, Ilorin. One of them, the Basorun Ogunmola statue in Ibadan (plate 17) is a war front action. In rendition, the equestrian figure at GRA, Ilorin (plate 18) is well expressed in realism, the horse leaped into the air, causing the rider to cling tenaciously to its body. The anatomical structure of both the horse and the rider were well studied and represented. The swing of the horse and the attendant effect on the rider were true to nature unlike the incongruous motion of the horse and the rider in the Basorun Ogunmola statue. The surface texture was also expressively treated, unifying the forms. The figure was given a light metallic patina. It was erected on an angular high pedestal. The pedestal approximately $300 \mathrm{~cm}$, in height, is well cut and properly textured with inset quartz stones. On the two sides of the sculpture are large water fountains whose springs add life into the sculpture.

Among the many abstract sculptural works in Ilorin only three portrayed visible Islamic traits vividly. Of the three, the one at Garin Alimi (plate 19) is the only one elaborately produced. it is a four-sided precast concrete double column architectural inverted bow form, and mounted on it is a cylindrical shape of about $50 \mathrm{~cm}$ in height on which interlace motif, the symbol of Arewa, that is the Northern Nigeria socio-political group was fixed. The Arewa intertwined motif is about $90 \mathrm{~cm}$. It was painted in "green white green", the Nigerian flag colour. This colour combination is commonly used for outdoor sculptures in Ilorin. The whole form occupies about $1800 \mathrm{~cm}$ radius land expanse with walkways around which beautiful flower was planted. 


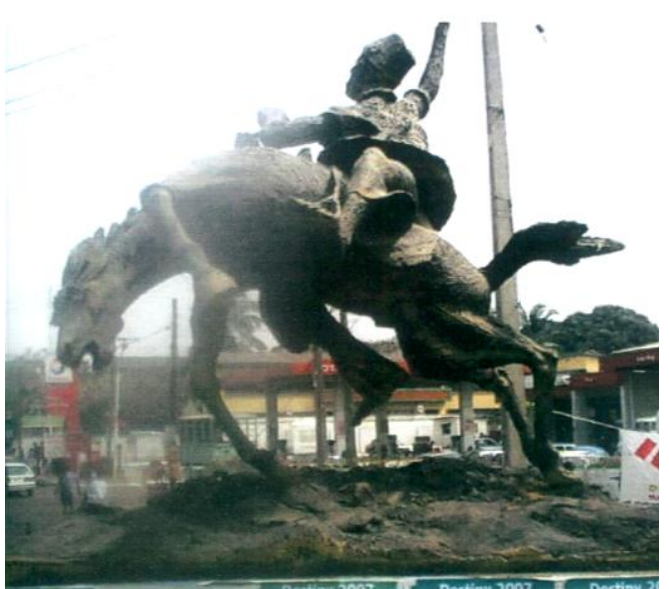

Plate 17

Obiora Madu, Basorun Ogunmola, cement $(180 \times 165) \mathrm{cm}, 1998$, Total Garden, Ibadan Photograph by Akintonde Moses, 2007

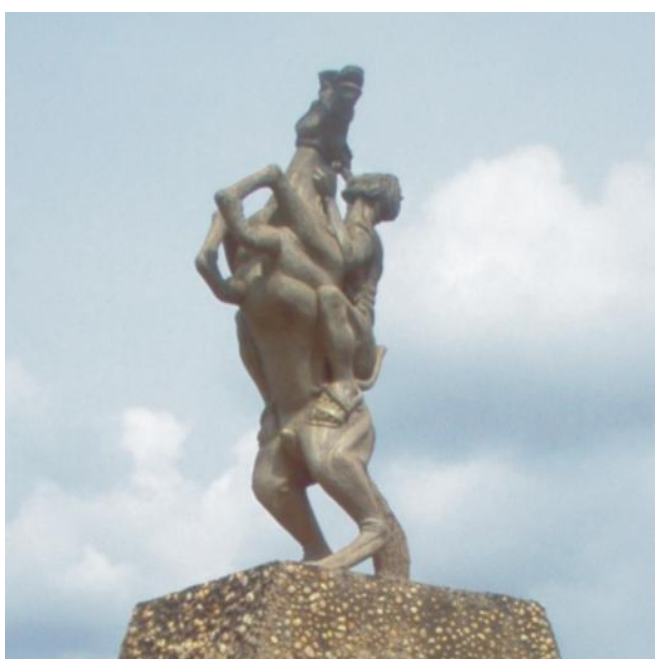

Plate 18

Equestrian figure, cement, GRA, Ilorin

Photograph by Akintonde Moses, 2007

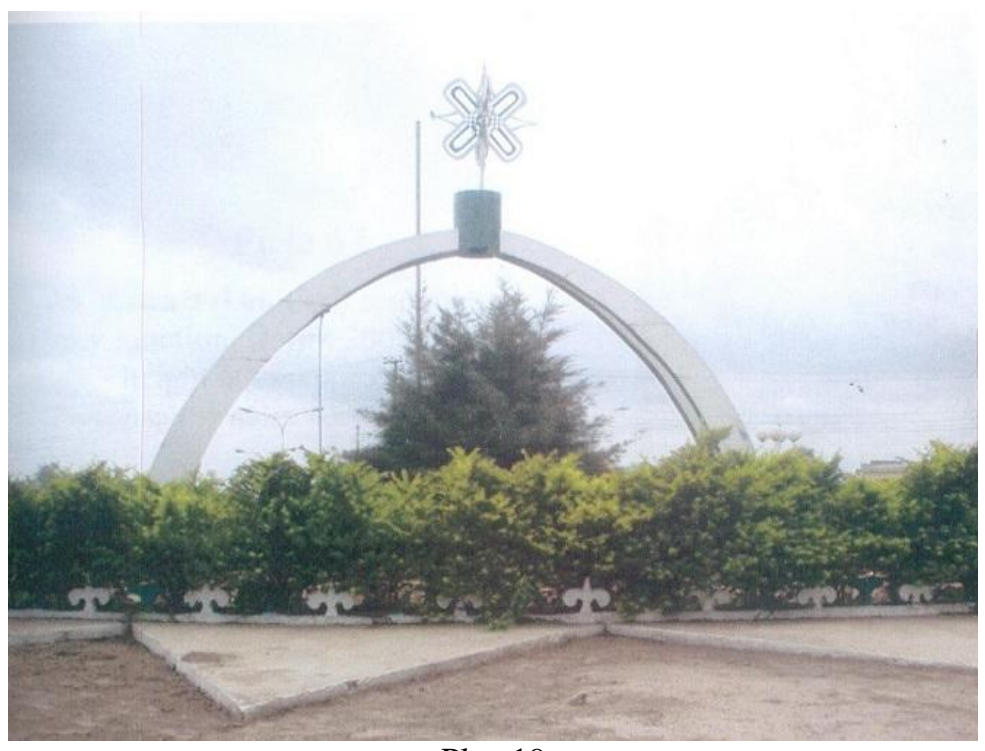

Plate19

An abstract sculpture with Arewa motif, cement and metal, height 540cm, 1987, Garin Alimi

Photograph by Akintonde Moses, 2007

\section{Conclusion}

Basically, outdoor sculptures in the Southwest of Nigeria are fairly large in number, forms expressions oscillate around realism more than abstract and naturalism in style. However, most of the images expressed are unskillfully produced. Themes of the works are rich, making possible an instant understanding of socio-political terrain of the Southwest in art historical perspective. The sculptures also reveal good handling of method of production in many works particularly those approached in moulding technique. Mustafa Toye, an Osogbo based sculptor, like many other sculptors in the Southwest zone of Nigeria observes the high interest of sculptors in the use of moulding directly with cement because it saves cost and time, and allows for good finishing of work.

Many sculptures made in fibre glass technique were poor in handling. Sculptures in carving, fordging, smithing, reponse are not found across the region while only a few numbers in metal cast are mainly noticed in private residents. Conclusively, the sculptors are still developing and it is hoped that in the near future works will be made with excellent skill, diverse media and techniques which will break the monotony of moulded figures and the use of cement as the main materials, thereby providing more aesthetic satisfaction. 


\section{References}

[1] C. Adepegba, Nigerian arts: Its tradition and modern tendencies (Ibadan, Jodad, 1995).

[2] W. Bascom, African art in cultural perspective: An introduction (New York, W.W. Norton, 1973a).

[3] W. Bascom, Creativity and style in African art, in D. Biebuyek (Ed,) Tradition and creativity in tribal art (Berkley, University of California Press, 1973b) 122-127.

[4] W. Fagg, Nigerian images, (Lagos, National Commission for Museums and Monuments, 1990).

[5] B. Idowu, Olodumare: God in Yoruba believe, (London, Longman, 1977).

[6] R. O. Rom Kalilu, Between tradition and record: A search for the legendary wood carvers of old Oyo, Ufahamu XX (11), 1992, 4963.

[7] R. O. Rom. Kalilu, Crisis in African art studies: Yoruba gourd carving and the need for historical concern in art history, in R. O. Rom Kalilu (ed), African art: Definition, forms and styles (Ogbomoso, Ladoke Akintola University of Technology, 1995) 28-42.

[8] R. F. Thompson, Yoruba Artistic Criticism, in Warren L.d'Azevedo (Ed.), The Traditional Artist in African Societies (Bloomington, Indiana University Press, 1973) 19-61

[9] R. Abiodun, The future of African art studies: An African perspective, paper presented at the National Museum of African Art, Smithsonian Institution, Washington D .C. 1987. 65-87

[10] F. Odiboh, Outdoor sculpture in Lagos metropolis, m. a. diss. in visual Arts, Institute of African Studies, University of Ibadan, Ibadan, 1987.

[11] G. Adewolo, Outdoor sculpture in Ibadan metropolis, m. a. diss., in Visual Arts, Institute of African Studies, University of Ibadan, Ibadan, 1999.

[12] M. A. Akintonde, Outdoor sculpture in Osun state: Emergence and development, International Journal of African Culture and Ideas, 4 (6), 2004, 15-27.

[13] M. A. Akintonde, Outdoor sculpture in Southwestern Nigeria 1900-2005: A survey of attitudes, doctoral diss., in Department of Fine and Applied Arts, Ladoke Akintonde University of Technology, Ogbomoso, 2009.

[14] A. Folarin, Urban sculpture in the metropolis, in B. Campbel, P. S. O. Aremu, A. Folarin and I. Ibigbami (Ed.), Diversity of Creativity in Nigeria (Ile-Ife, Department of Fine Art, Obafemi Awolowo University, 1989) 125-132.

[15] S. O. Ikpakronyi, Contemporary outdoor sculpture in Enugu and Owerri metropolis: Form and content, m. a. diss., in Visual Art Institute of African Studies, University of Ibadan, Ibadan, 1997.

[16] S. O. Ikpakronyi, Modern sculptures in Benin city: Their classification and cultural relevance. USO: Nigerian Journal of Art, 4 (1\&2), 2005, 19-37

[17] M. Graves, The art of colour and design (London, McGraw-Hill, 1951).

[18] R. Abiodun, H. J. Drewal and J. Pemberton III, Yoruba art and aesthetics (Zurich, Museum Rietberg, 1991)

[19] R. Herbert, Modern sculpture: A concise history, (New York, Thames and Hudson, 1989) 